\title{
Esbozo de la iniciativa para la conservación de la ruta huichol a Huiricuta y de sus santuarios naturales asociados (México)
}

Recibido: 2 Outubro 2008 / Aceptado: 5 Novembro 2008
(C) IBADER- Universidade de Santiago de Compostela 2008

Resumen De entre las diferentes rutas de peregrinación que la sociedad huichol tiene a lo largo de su geografía cultural, la ruta a Huiricuta por los sitios sagrados naturales, destaca por su jerarquía, importancia ritual y frecuencia de uso. El itinerario discurre a lo largo de los estados de Nayarit, Jalisco, Zacatecas y San Luis Potosí, y se inserta en un mosaico de territorios con particularidades biogeográficas, históricas y culturales, cuyos principales atributos son analizados. Es sobre este escenario donde se ha puesto en marcha una iniciativa consensuada para preservar su patrimonio biológico y cultural a partir de criterios de conservación, desarrollo sostenible y defensa de derechos y cultura indígenas; ello con el fin de reivindicar el papel trascendental que juegan los itinerarios culturales y de los sitios sagrados naturales. Se presentan finalmente algunos de los logros y avances obtenidos, a través de programas, mecanismos legales y actuaciones concretas.

Palabras clave Ruta huichol · paisaje cultural · santuario natural $\cdot$ conservación

Abstract Among the different pilgrim routes through the huichol sociocultural geography, the route to Huiricuta through natural sacred places is outstanding for its hierarchy, ritual significance and frequency of use. The route runs though the states of Nayarit, Jalisco, Zacatecas and San Luis Potosi, a patchwork of territories with biogeographic, historical and cultural particulars, whose main attributes are analyzed. This is the setting for the consensual iniciative to preserve the biological and cultural

Joaquín Giménez de Azcárate

Departamento de Botánica. Escola Politécnica Superior. USC 27002 Lugo

Humberto Fernández Borja

Conservación Humana Asociación Civil. Zacatecas 110. Col. Roma. 06700 México D.F. heritage on the basis of conservation, sustainable development and the defense of indigenous cultures and human rights criteria, in order to claim the crucial role played by the conservation of cultural itineraries and the natural and sacred places. The achievements and progress made, through programs, legal mechanisms and particular actions, are documented.

Key words Huichol route - cultural landscape ' natural sanctuary $\cdot$ conservation

\section{Introducción}

El estudio de los itinerarios culturales y el de su entorno natural, constituye un interesante desafío debido a su carácter evocativo, dinámico y multidimensional, a la vez que ofrece nuevas aproximaciones y herramientas para la protección del territorio. Sus características espaciotemporales, ecológicas y culturales, junto con sus funciones, significados y propósitos, brindan una veta extraordinaria para abordar, desde el enfoque holístico, su diagnosis.

La aplicación y desarrollo de conceptos como santuario natural o paisaje cultural permite reflejar las múltiples interacciones entre las personas y su entorno natural a lo largo del tiempo y del espacio (Von Droste et al. 1995; Fernández 1999; Suárez 2005). Es así que se alcanzan enfoques más humanistas basados en la identidad y resonancia cultural de las tradiciones desarrolladas en íntimo contacto con la naturaleza de la cual se nutren. En este sentido se asume y respalda el concepto de paisaje ritual de Broda (2001), entendido como una construcción histórica y una práctica cultural, circunscrita a un territorio, y a sus mundos social y natural inherentes.

El territorio mexicano reúne un capital natural vasto e invaluable desarrollado en escenarios ecológicos heterogéneos, en los cuales, durante milenios, se han recreado valores y conocimientos únicos, relacionados con el manejo y uso diversificado del territorio y de sus recursos. 
Sin embargo este legado etnocultural y su contexto natural, se encuentran seriamente amenazados por actuaciones carentes de escrúpulos vinculadas al desarrollismo socioeconómico imperante (apertura de viales, infraestructuras hidráulicas y mineras, tendidos eléctricos, explotaciones forestales, promociones turísticas..), que, en la mayoría de las ocasiones, desconoce o minimiza tal herencia. Aunque existe un consenso general a la hora de preservar este patrimonio, la incidencia de tales actuaciones tiende a erosionarlo y diluirlo, cuando no lo desmantelan. Es por ello que ante esta crisis ambiental y social, el Pueblo Huichol, a través de las autoridades tradicionales de sus centros ceremoniales, y las comunidades conservacionista y científica, coordinadas desde Conservación Humana A.C., han juntado y coordinado sus esfuerzos para aliarse $y$ enfrentarse el reto común de salvaguardar un patrimonio que trasciende el tiempo y las fronteras, y que se corresponde con el ingente acervo etnográfico y biológico vinculado a sus rutas tradicionales de peregrinación y a sus paisajes asociados.

La idea parte del conocimiento que las sociedades indígenas tradicionales tienen sobre las formas sostenidas del uso de la biodiversidad y del papel que éstas tienen en el desarrollo rural amistoso y culturalmente apropiado (Dömpke 1998), hasta llegar a la revalorización

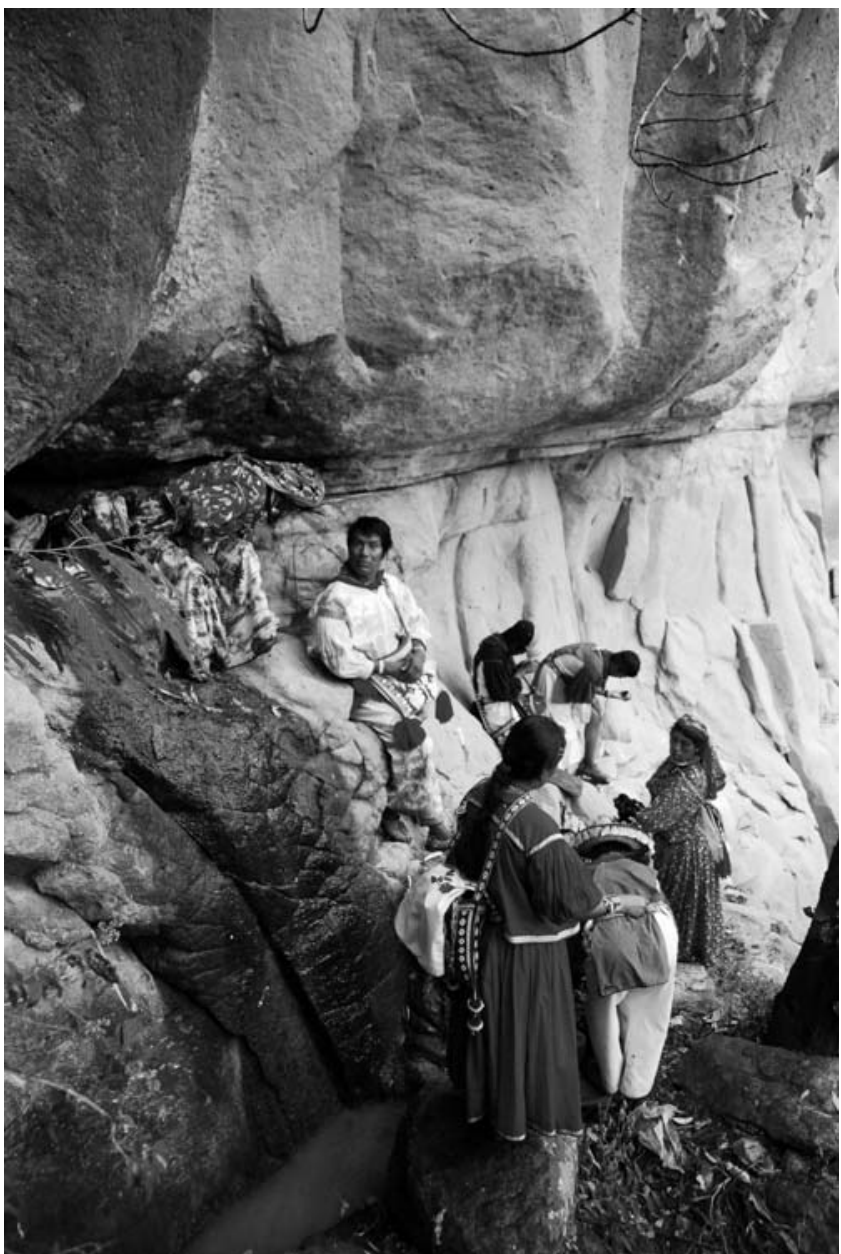

Fotografía 1.- Ofrenda de peregrinos en un manantial sagrado de la Sierra Madre (Jalisco) epistemológica de su legado. El sentido de paisaje ritual considerado como espejo del cosmos que contiene la memoria histórica del pueblo que lo concibe (Broda 2001) es asumido, respaldado y entendido como una construcción histórica y una práctica cultural, circunscrita a un territorio, y a sus mundos social y natural inherentes. Se trata de integrar bajo un mismo prisma la preservación de las rutas culturales y de su entorno, integrando lugares, bienes y valores ecológicos y culturales, de orden material e inmaterial, asociados a su finalidad específica y funcionalidad histórica (Suárez 2005). Es en este contexto donde los sitios sagrados naturales o santuarios naturales, intrínsecos a muchos de los itinerarios culturales, realzan su singularidad.

Las tradiciones relacionadas con el peregrinaje por las rutas ancestrales marcan las pautas para leer y estudiar los códices del paisaje, fomentando así la pervivencia y revitalización cultural de un pueblo, al constituir estas peregrinaciones verdaderas "universidades itinerantes". Dichas tradiciones suceden, de una $u$ otra manera, en casi todos los continentes. En América y especialmente en México, se desarrollan en territorios extensos que brindan servicios ambientales relevantes a través de corredores de interés combinado, biológico y cultural. Estos corredores ofrecen un marco privilegiado donde la tolerancia y el entendimiento mutuo pueden fortalecer el capital social y el desarrollo sostenible a partir de raíces culturales profundas. El caso más evidente sucede con la geografía cultural del Pueblo Indígena Huichol aquí tratada; la de los seris, yaquis, tarahumaras o pápagos en el noroeste de México son otros ejemplos cercanos a mencionar.

\section{Objetivos}

El propósito central planteado es dar a conocer los avances obtenidos en los trabajos de gabinete, cabildeo y campo vinculados a la iniciativa aquí planteada. Dada la importancia del marco de referencia en el que se desenvuelve dicha iniciativa se ha creído conveniente abordar los aspectos concernientes al escenario de la geografía huichol y al significado histórico y cultural de su principal ruta de peregrinación a Huiricuta.

Como objetivo complementario está el de presentar y comentar el panorama socio-ambiental y ecológico que caracteriza el itinerario analizado, haciendo especial hincapié en aquellos atributos que justifican y respaldan las tareas de conservación y desarrollo armónico y participativo que se han comenzado a implementar.

\section{El escenario: Los huicholes y sus rutas de peregrinación}

Las sociedades mesoamericanas que hoy conocemos como los huicholes conforman una de las culturas nativas que ha sobrevivido con mayor vitalidad a los avatares de la historia americana, al haber conservado buena parte de su acervo étnico, cultural, social y religioso-ceremonial (Weigand 2002). Esto ha sido posible gracias a la 
accidentada topografía de sus territorios, a su organización política descentralizada y a su capacidad de adaptación al entorno histórico. Sin embargo, la fuerza principal de su reproducción cultural es la tenacidad colectiva para cumplir con las tradiciones ancestrales. Habitan en rancherías dispersas y pequeños poblados en un territorio de más de 400,000 hectáreas, al sur de la Sierra Madre Occidental, donde convergen los estados de Jalisco, Nayarit, Zacatecas y Durango; este territorio se corresponde aproximadamente con la mitad del área original de ocupación en la región del Gran Nayar (Lira 2003). Su población censada es de 30,700 personas (INEGI 2006), aunque hay que considerar que más de la mitad viven emigrados fuera de su territorio, estimándose su población en la Sierra en unos 19.000 individuos (Weigand 1992, 2002). Su organización política es compleja, ya que las jerarquías tradicionales se imbrican con las modernas. Hacia la mitad del sigo XX, después de la Revolución Mexicana y la Guerra Cristera, el gobierno central los ha reconocido como tres comunidades agrarias y diversos ejidos adyacentes, que comprenden a cinco tribus o gobernancias, entre las que existen diferencias notables de dialecto, ritual e indumentaria (Weigand 2002). Estas gobernancias son: Tuapurie o Santa Catarina Cuexcomatitlán, Huautia o San Sebastián Teponahuastlán, Tuxipa o Tuxpan de Bolaños, Tatei quié o San Andrés Coahmiata y Tsatsitsiare o Guadalupe Ocotán. La base del enjambre social y del esquema organizativo tradicional son los centros ceremoniales o tuquipa.

El ceremonialismo agroecológico es el componente preponderante de su vida religiosa. En él los ciclos rituales están asociados a actividades como pedir la lluvia, preparar la tierra, obtener buena cosecha o cazar el venado. La función educativa de los ciclos rituales es fundamental para su devenir histórico ya que con ellos se recrea y transmite el legado ancestral, mediante cantos, relatos y rituales sofisticados. Este legado, además de los conocimientos chamánicos, religiosos o médicos, incluye el uso diversificado y racional de los recursos naturales, y en particular la conservación de variedades endémicas de especies cultivadas (Nieves et al. 2004).

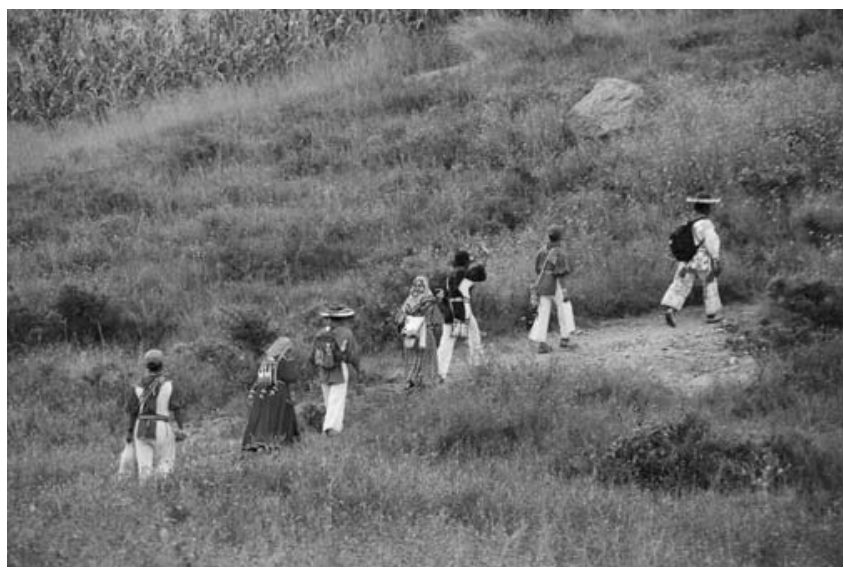

Fotografía 2.- Peregrinos camino a un santuario natural en la vertiente occidental de Sierra Madre (Nayarit)

\section{Los antecedentes de las rutas}

Las actuales rutas de peregrinación huicholas son remanentes de los ancestrales itinerarios de intercambio ligados a las rutas comerciales marítimo-terrestres que desde regiones tan distantes como el norte de Chile o el suroeste de los Estados Unidos permitieron un irregular pero relevante contacto por diferentes enclaves de la costa pacífica mexicana (Hers 2000; Weigand \& García 2000). Éstos y otros puertos intermedios eran, a su vez, puntos de conexión hacia tierra adentro. Aquellos intrépidos navegantes comerciaron los materiales más preciados y actuaron como transmisores y difusores de nuevas ideas, tecnologías, materiales o especies de flora y fauna (Beltrán 2001).

Conforme se estructuraban los sistemas de trueque, se fueron creando códigos de información simbólica, originando el intercambio ceremonializado. Pese a que el territorio ocupado por los antepasados de los huicholes tuvo una oferta escasa de bienes preciosos, su posición geográfica permitió que participaran en el comercio entre los puertos de las llanuras costeras y los poblados de tierra adentro. Así, rutas como de la turquesa o las de propagación del maíz y del frijol, contribuyeron en el tejido de vínculos entre Mesoamérica y el Norte de México y el suroeste de los Estados Unidos. La lista de bienes es larga y diversa: minerales como la turquesa, la obsidiana, la plata o el cobre; subproductos de origen animal y vegetal como conchas de moluscos, plumas, pieles, fibras, maíz, chile, tomate, cacao; plantas y hongos enteógenos como el peyote, el tabaco o el psilocibe, o bien cerámica, sal, e incluso seres humanos como esclavos o concubinas (Weigand 2002). Las especies enteógenas mencionadas tuvieron una función importante, pero poco y temerosamente entendida en la cosmovisión novohispánica. Tan es así, que para consolidar el proceso de la Conquista dichas especies fueron satanizadas y sus usuarios penados con la hoguera durante la Inquisición. Desgraciadamente, ésta y otras estrategias de colonización, como la negación de los sistemas tradicionales educativos

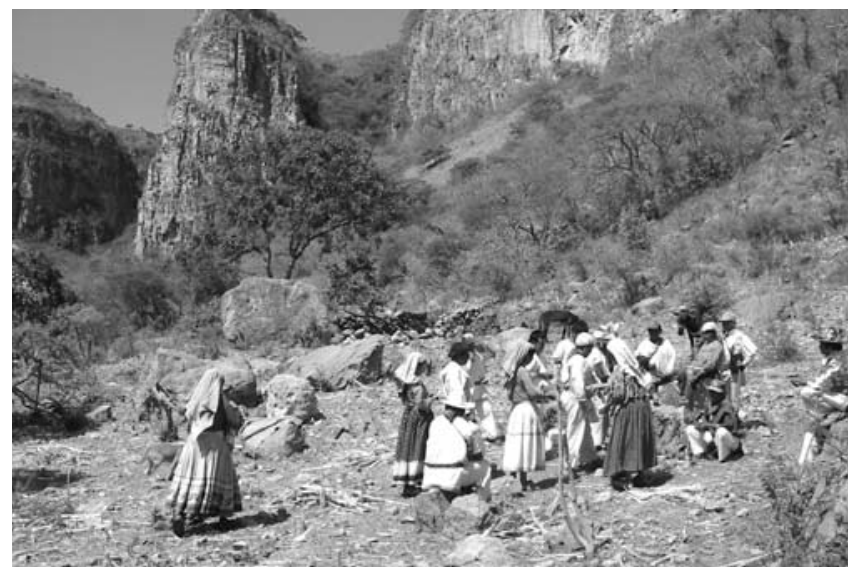

Fotografía 3.- Ofrenda en una milpa de Sierra Madre (Jalisco) 
o la imposición lingüística, entre otras, han prevalecido hasta el presente.

\section{La ruta a Huiricuta por los sitios sagrados naturales}

Con base en los antecedentes expuestos, las rutas contemporáneas de los huicholes se interpretan como el remanente más notable de los itinerarios de intercambio prehispánicos; los itinerarios conducen hacia los santuarios naturales que se encuentran en todas las direcciones: las montañas del norte en tierras tepehuanas dentro de la misma Sierra Madre Occidental; rumbo al oeste, hacia los humedales costeros nayaritas; al sur, donde se localiza el lago de Chapala. Incluso aún hay ancianos que recuerdan una ruta al Valle de México. En cualquier caso una constelación de sitios sagrados naturales e itinerarios de peregrinación se integran al paisaje como resonancia cultural de un pueblo a través de múltiples interacciones.

Pese al carácter multidireccional de las peregrinaciones, la ruta que desde el territorio huichol, en Sierra Madre, se dirige a Huiricuta en el altiplano Potosino (Figura 1), sobresale por su relevancia jerárquica, la frecuencia con que se utiliza y el número de usuarios. La Ruta a Huiricuta es el bien relictual más importante de esta red de rutas, y ha sobrevivido a pesar de los cambios irreversibles sufridos a partir del impacto de la conquista. Al hablar de este itinerario nos referimos a una "trenza" de veredas, terracerías, caminos e incluso carreteras, que se van sucediendo según diversos factores. Cabe destacar la presencia de vestigios viales del periodo novohispano, que constituyen caminos reales y "callejones" pecuarios. Su trazo, con dirección oeste-noreste, atraviesa las barrancas y mesas donde se imbrican los estados de Jalisco y Zacatecas, para luego cruzar transversalmente éste último, pasando por su capital; ya en el estado de San Luis Potosí, la ruta se dirige hacia la Sierra de Picachos del Tunalillo, para desembocar en Huiricuta y en la contigua Sierra de Catorce (Fernández \& G. Azcárate 2005). Este itinerario se complementa con la ruta a Jaramara, o de los muertos, en la costa nayarita.

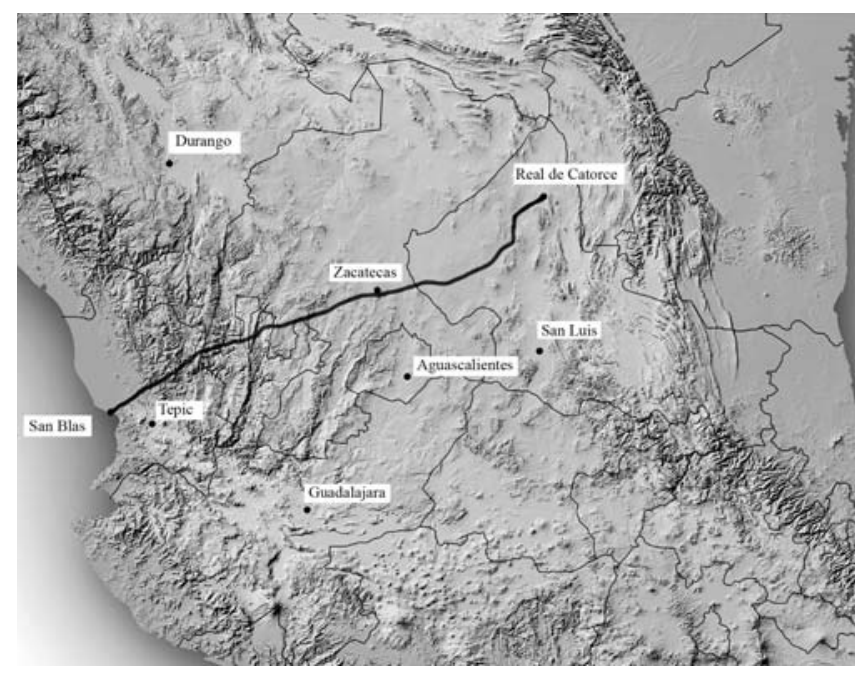

Figura 1.- Trazo del itinerario a Huiricuta (Real de Catorce) y a Jaramara (San Blas)
A lo largo de la Ruta, habitan deidades y espíritus de ancestros, de ciertas especies (como el lobo o el venado) o bien de procesos y fenómenos atmosféricos y geoecológicos como la formación de las nubes, de la lluvia y del viento, la fertilidad de la tierra o la recarga de acuíferos $y$ el afloramiento de veneros. Los huicholes identifican también a algunos de estos elementos como "hermanos mayores" o "maestros", los tamátsite, los cuales influirán positiva o negativamente en su destino. Las deidades y espíritus tienen su morada, justamente, en enclaves sagrados, razón por la cual se han conservado durante siglos como espacios primigenios de especial relevancia ecológica y cultural. Los sitios sagrados naturales se localizan en islotes, ríos, lagunas, manantiales, bosques, cerros, cuevas o rocas. En ciertos lugares se presentan concentraciones de sitios sagrados, formando paisajes también sagrados como lo son Huiricuta, Xurahue Muyeca (Sierra de Cardos en Zacatecas) y la propia Sierra de los Huicholes (CHAC, 2004). En el transcurso de la Ruta existen otros hitos tangibles del paisaje de menor jerarquía ceremonial, que no son necesariamente "sagrados", los cahuíte, que son la huella de los cacauyárite, semidioses que se petrificaron y modelaron el paisaje cuando fallaron las pruebas de la creación en el tiempo primordial.

Durante el periodo novohispano, e incluso después, se han desarticulado los pilares económicos de los pueblos indios y se ha transformado su entorno natural por la creciente impacto de las actividades ganaderas y forestales (Toledo \& Ordóñez 1998). Asimismo durante las últimas décadas la "globalización" y las políticas de integración han acelerado la descomposición de su tejido social. Pese a ello la ruta a Huiricuta se ha mantenido de forma semiclandestina para así preservar su vigencia y espiritualidad; y lo ha logrado hasta ahora, manteniendo los compromisos que la justifican y sostienen. Por otro lado los procesos de degradación y fragmentación del entorno, amenazan su sostén esencial que es precisamente su vínculo con la naturaleza (Weigand \& García, 2000). El vigor y la riqueza de los ciclos rituales, y los significados culturales que confieren al paisaje los huicholes, representan un testimonio excepcional al constituir el remanente vigente más representativo y vital del gran enjambre de rutas de intercambio que durante milenios enriqueció social y culturalmente a América.

El propósito central de la peregrinación a Huiricuta es seguir los pasos de los antepasados visitando las deidades y espíritus que habitan en los sitios sagrados naturales que jalonan la Ruta; ello con el fin de lograr una relación favorable que confiera a los peregrinos sabiduría, guía espiritual y bienestar, incluyendo éste último tanto salud como lluvia para asegurar la cosecha. Para cada caso, las visitas a los distintos sitios llevan asociadas ofrendas y rituales particulares. El incumplimiento de las obligaciones puede traer consigo penalidades y castigos. Otro de los propósitos críticos de las peregrinaciones es la experiencia educativa y formativa, su función como universidad itinerante, donde los neófitos aprenden lo relacionado con la ruta, la tradición y "el costumbre". Los santuarios y los cahuite poseen significados espirituales, biogeográficos, sociales o históricos y constituyen nodos que contienen registro del legado tribal que se rememora al caminar, si se 
cuenta con la guía adecuada. Así, el itinerario se convierte en la lectura de un códice extendido en el paisaje.

Ya en Huiricuta tiene lugar la "cacería del venado" simbolizada a través de la batida y recolección ceremonializada del peyote (Lophophora williamsii). El aprovisionamiento del cactus tiene fin esencialmente ritual, si bien puede intercambiarse en el camino de regreso con rancheros que lo utilizan para fines medicinales o, en la sierra, con los vecinos coras, mexicaneros o tepehuanos. Tras pasar varios días en este templo sagrado natural, los huicholes emprenden el camino de regreso, dejando ofrenda en muchos de los sitios sagrados visitados en la ida.

Hasta mediados de los años setenta el itinerario era realizado a pié y con remudas de apoyo para el bastimento. Los grupos de peregrinos eran bastante numerosos (hasta 200 personas) y generalmente estaban integrados por representantes de uno a varios clanes familiares de una misma comunidad. La irrupción de los vehículos motorizados, en ocasiones fomentados desde instancias gubernamentales, ha propiciado una diversificación de las formas de afrontar el recorrido, así como del número de componentes de los grupos. Actualmente las camionetas son el vehículo más utilizado, aunque muchas veces éstas actúan como vehículos de apoyo de los peregrinos que caminan total o parcialmente el itinerario. También es frecuente, aunque en menor proporción, que pequeños grupos familiares o individuos solos, hagan la totalidad del recorrido a pié sin apoyo logístico alguno. El período más habitual es el que prosigue al de la cosecha, durante el invierno.

\section{Importancia ecorregional}

La aportación más relevante de la cultura huichol, que depende en gran medida de la integridad de los santuarios naturales que visitan, es haber preservado una cosmovisión íntimamente ligada a la naturaleza cuyo último fin es el mantenimiento de relaciones positivas con los ancestros que controlan a la naturaleza y a sus fenómenos. Paralelamente ha servido como referencia contemporánea de uso, conocimiento y preservación de la diversidad biológica asociada al corredor por el que transitan en sus peregrinaciones. Así la Ruta a Huiricuta constituye además un bien excepcional que atraviesa la porción meridional de tres ecorregiones de relevancia planetaria por su aportación a la biodiversidad (Rzedowski 1991; Mittermeier et al. 1999; Olson \& Dinerstein, 2002): el Golfo de California, la Sierra Madre Occidental y el Desierto Chihuahuense. La primera integra ecosistemas marinos y litorales de gran productividad; en ella están presentes el $35 \%$ de las especies de mamíferos marinos del mundo; sus islas constituyen un área notable de anidación de aves así como sirven de lugar de reposo para las especies migratorias. En su planicie costera se localizan humedales de gran importancia ecológica como los manglares de Marismas Nacionales, de los más extensos y mejor conservados en el litoral del Pacífico de América.

La topografía compleja y los espectaculares rangos altitudinales de la Sierra Madre Occidental favorecen la secuencia catenal de una amplia gama de formaciones vegetales entre las que destacan bosques tropicales caducifolios y subcaducifolios, bosques espinosos, matorrales, pastizales, bosques de galería o bosques de pino-encino, todas ellas prolijas en endemismos y refugio de flora y fauna singular.

El Desierto Chihuahuense está flanqueado por las sierras Madre Oriental y Madre Occidental, y en él se desarrollan una gran diversidad de comunidades xerofíticas, halófitas y pastizales. Está conformado por planicies aluviales, bolsones endorreicos y serranías dispersas cubiertas de bosquetes. De forma puntual y asociada a los fondos de los bolsones endorreicos o a los afloramientos de agua aparecen comunidades herbáceas de carácter gibsófilo y/o hidrófilo.

Por lo anterior vemos que la Ruta articula un corredor que, a modo de banda, atraviesa estas ecorregiones, con representaciones de hábitats singulares y especies amenazadas, endémicas o relictuales, lo que en ciertos casos ha merecido su inclusión en alguna de las categorías de "Áreas Prioritarias para la Conservación". Éstas han sido identificadas así tanto por organizaciones nacionales (CONABIO, SEMARNAT - CONANP), como por instituciones internacionales (UNESCO, RAMSAR).

Estas áreas se integran en algunas de las figuras expuestas en la Tabla 1, las cuales son atravesadas por el corredor o bien están en la zona de influencia de sus paisajes asociados. Para su elaboración nos hemos basado en Fernández \& Becerra (1995), Arriaga et al. (2000) y Conabio (2004).

\begin{tabular}{llll}
\hline \multicolumn{1}{c}{ RTP } & \multicolumn{1}{c}{ RHP } & \multicolumn{1}{c}{ AICAS } & \multicolumn{1}{c}{ AP } \\
\hline + Marismas Nacionales & + Río Baluarte -Marismas & + Marismas Nacionales & + APRN Cuenca Alimentadora del \\
+ Cuenca del Río Jesús María & Nacionales & + El Carricito & Distrito Nacional de Riego No. 043 \\
& + San Blas - La Tovara & + Monte Escobedo & + Zona Protectora Forestal de la \\
+ Tokio & + Camacho - Gruñidora & + Sierra de Valparaiso & + Huiricuta Reserva Natural y \\
+ Sierra los Huicholes & + Venado- Moctezuma & + Sierra de Catorce & Cultural \\
+ Pastizales gibsófilos de & &
\end{tabular}

Tabla 1.- Regiones prioritarias de la CONABIO y áreas protegidas atravesadas por la Ruta o en su área de influencia. Acrónimos: RTP: Región Terrestre Prioritaria. RHP: Región Hidrológica Prioritaria. AICAS: Áreas de Importancia para la Conservación de las Aves. AP: Áreas protegidas. APRN: Área de protección de recursos naturales 


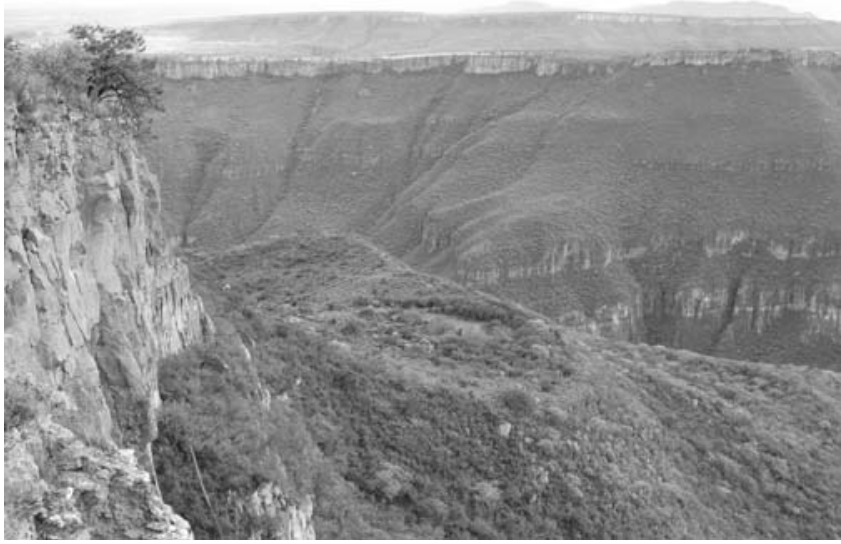

Fotografía 4.- Aspecto otoñal de selva baja caducifolia en el valle del río Colotlán (Zacatecas)

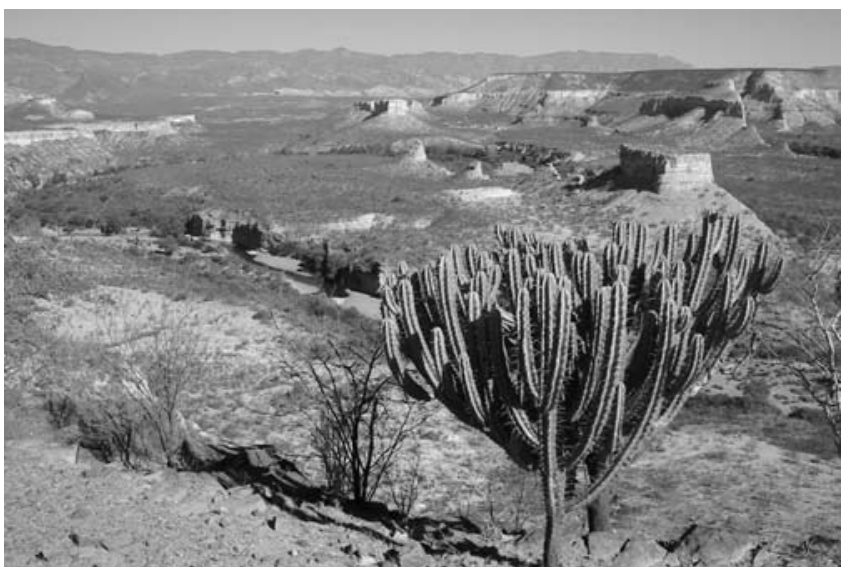

Fotografía 5.- Cañón del Chapalagana (Zacatecas). En primer plano un garambullo (Myrtillocactus geometrizans)

En los últimos cinco siglos, el peregrinaje también ha tenido la función de contacto e intercambio con la cultura mestiza, en buena parte responsable de los procesos de transformación del paisaje comentados anteriormente. Algunos se han producido de manera armónica, dando lugar a sistemas silvo-pastorales análogos a las dehesas ibéricas, los cuales se conformaron a partir de la introducción del ganado en la época colonial y posterior. El parentesco sistemático de sus principales componentes (Quercus spp.) y las vías pecuarias que lo atraviesan, que en ocasiones constituyen asimismo caminos reales y rutas prehispánicas de intercambio, realzan esta peculiar y única simbiosis ecológica, social y cultural.

\section{Avances y perspectivas}

Con base en los apuntes y consideraciones plasmados anteriormente y bajo acuerdo con las autoridades tradicionales huicholas, Conservación Humana ha emprendido esta iniciativa dirigida a la conservación y puesta en valor del patrimonio natural y cultural de las rutas, santuarios y paisajes, así como al fomento del desarrollo sostenible entre los habitantes de los territorios

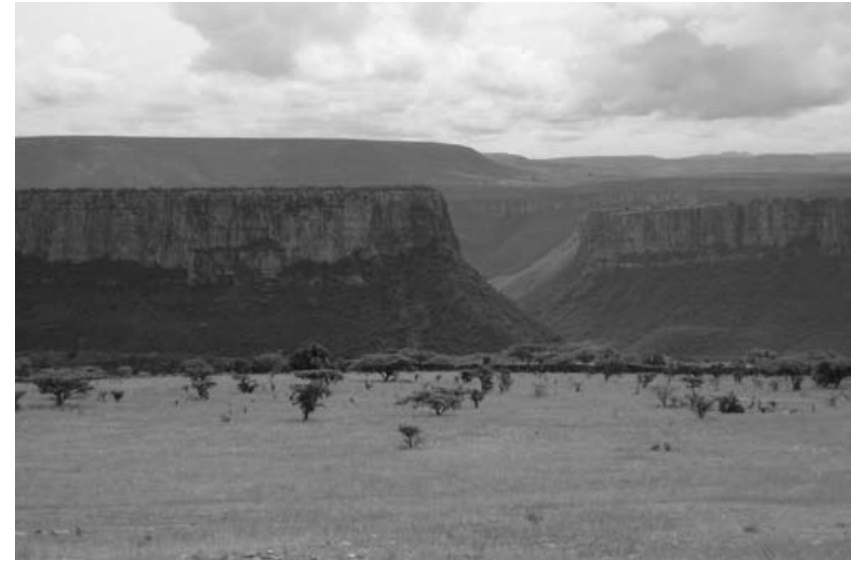

Fotografía 6.- Pastizal con huizaches (Acacia schaffneri). Al fondo las barrancas de San Luís el Gato (Zacatecas)

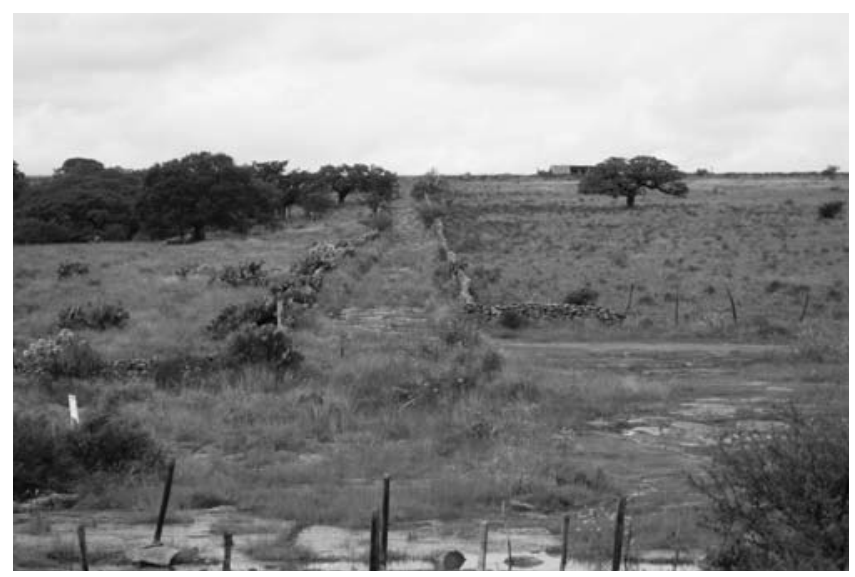

Fotografía 7.- Vía pecuaria (callejón) atravesando superficies adehesadas en Monte Escobedo (Zacatecas)

considerados. Para alcanzar este objetivo, desde 1994 se trabaja transversalmente con instituciones de los tres órdenes de gobierno, especialistas de diferentes centros de investigación y otros grupos organizados de la sociedad civil de México y el extranjero.

La estrategia de la iniciativa se centra en impulsar la aplicación de herramientas de conservación y planeación del territorio, articuladas con instrumentos de política económica, social y cultural. Así mismo promueve y se sustenta en recursos conceptuales desarrollados recientemente por la comunidad internacional, incluyendo organismos como la UNESCO, el ICOMOS, la UICN y la Unión Europea. Algunos de estos recursos, como los paisajes culturales, los sitios sagrados naturales o los itinerarios culturales, ofrecen una oportunidad de innovación en el fortalecimiento del capital social y la conservación del patrimonio natural y cultural en México.

Entre otros logros, se ha impulsado la creación, en el año 1994, de la Reserva Natural y Cultural de Huiricuta en el estado de San Luis Potosí, lo que constituyó un precedente jurídico tanto en las leyes del ámbito cultural como ambiental de dicho estado. En ambas se reconocen y 
protegen por primera vez en la Federación, una ruta tradicional de peregrinación y sus paisajes culturales asociados que incluyen los sitios sagrados naturales reunidos en Huiricuta. Años más tarde, a partir de los estudios realizados al amparo del inventario y diagnosis del medio natural, que incluyeron la adyacente Sierra de Catorce, se han inventariado, caracterizado y cartografiado sus componentes biológicos y recursos naturales. De forma complementaria se efectuaron los trabajos correspondientes al ámbito cultural que permitieron identificar los atributos etnográficos y cartografiar el trazo de la ruta. Los resultados obtenidos sirvieron para que en 2000 se propusiera la ampliación de la Reserva a $141.000 \mathrm{Ha}$ y la inclusión de los $138 \mathrm{kms}$ de ruta que transcurren por dicho Estado desde el límite con el vecino de Zacataecas. Así mismo se elaboraron el Plan de Manejo y el SIG de la Reserva, y se implementaron docenas de experiencias de desarrollo comunitario dirigidas a resolver o paliar algunos de los problemas que hemos ido detectando a lo largo la Ruta y en la misma Reserva de Huiricuta. Durante estos últimos 8 años se abordaron talleres, proyectos y experiencias relaciondas con el derecho de paso, la señaléctica, la remoción de obstáculos, el mantenimiento y limpieza de los caminos, la conservación y restauración de los santuarios sagrados naturales, o la puesta en marcha de planes pilotos de agricultura y manejo sostenible de agua.

Al hilo de la estrategia aquí resumida se han iniciado, desde el año 2005, los contactos y trabajos pertinentes para aplicarla en el estado de Zacatecas. La favorable disposición encontrada y los antecedentes y avances acaecidos han llevado al Instituto de Ecología y Medio Ambiente de Zacatecas a encargar a Conservación Humana A.C. el estudio informativo para la propuesta de declaratoria de área natural protegida da la ruta Huichol en tal estado, mismo que se entregó a finales de 2007. De nuevo con base en los inventarios y diagnosis efectuados, en colaboración con diferentes especialistas, se contempla el establecimiento de dos superficies disyuntas unidas por el trazo de la ruta. La primera, de oeste a este, es "polígono Monte Escobedo - Cardos", de $232.000 \mathrm{Ha}$, en el que se engloban las sierras que le dan nombre así como parte de

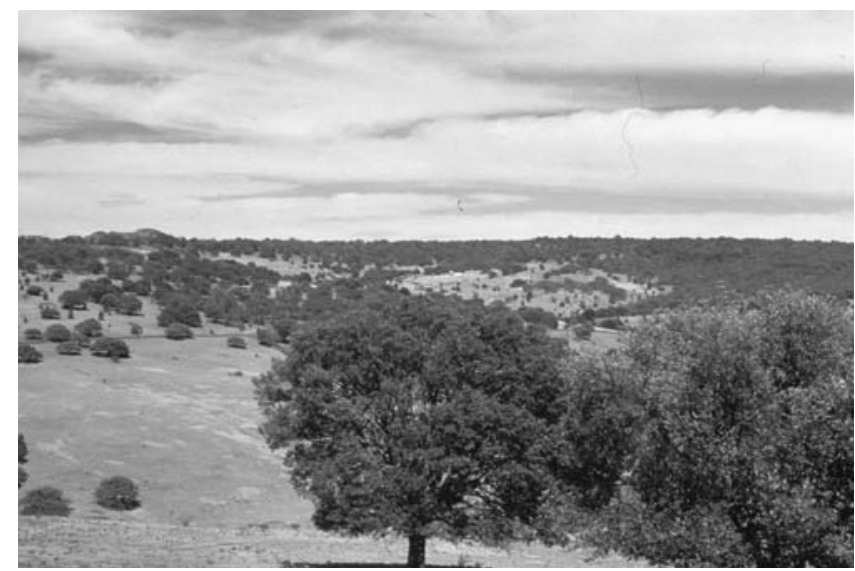

Fotografía 8.- Peregrinos camino a un santuario natural en la vertiente occidental de Sierra Madre (Nayarit) la de Valparaíso y algunas de sus planicies y piedemontes. La segunda, "polígono Zacatecas", de $13.900 \mathrm{Ha}$, se emplaza en la periferia de la ciudad de Zacatecas. El trazo lineal contempla un total de $173 \mathrm{kms}$, los que recorre la ruta desde los límites del Estado con Jalisco y San Luis Potosí.

Hay que mencionar la presencia de dos áreas protegidas con categoría de Zona Protectora Forestal (ZPF), creadas hace unos 80 años pero que nunca funcionaron: La ZPF "Ciudad de Zacatecas" y la ZPF "Cuenca alimentadora del Distrito Nacional de Riego no. 43 Estado de Nayarit ", que cubre buena parte de dicho estado, el norte de Jalisco y de Aguascalientes, el sur de Durango y una buena porción del oeste y sur de Zacatecas, incluyendo casi todo el polígono Monte Escobedo - Cardos. Esta última ZPF fue recategorizada en el 2002, pero la delimitación y zonificación precisa no se ha definido aún. Sin embargo se está avanzando en la incorporación de los planteamientos aquí comentados para su delimitación y zonificación.

Otros sitios con algún tipo de protección dentro del Corredor tratado son el sitio de patrimonio cultural al lugar sagrado Tatei Jaramara en el Municipio de San Blas, decretado en 1990 por el Gobierno de Nayarit. Pese a que fue un precedente notable, la protección se da en un área reducida, menor a $1 \mathrm{Ha}$ que comprende uno de los puntos culminantes del paisaje sagrado huichol, en aguas del Pacífico. Otro lugar seleccionado para su protección es Jauxa Manacá en Cerro Gordo, Durango, establecido bajo un acuerdo tepehuano-huichol; así como en San Blas, se contempló tan solo un área pequeña del entorno sagrado correspondiente. Otro sitio a mencionar es Xrapavilleme, actualmente venerado en la Isla Alacranes de la Laguna de Chapala, en sustitución de la Laguna Magdalena, igualmente en Jalisco y que fue desecada durante la década de los sesenta; para este lugar existen diversos acuerdos de protección entre huicholes, municipio y gobierno estatal (CHAC 2001).

En el orden internacional, toda la Ruta a Huiricuta, incluyendo sus paisajes vinculados, está inscrita en la Lista Indicativa Mexicana de la Convención de Patrimonio Mundial de la UNESCO, en la categoría de itinerarios

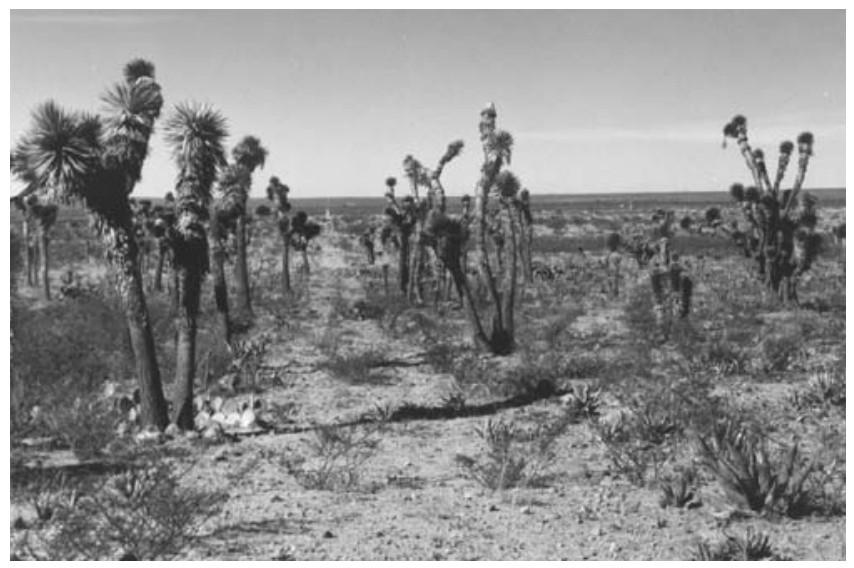

Fotografía 9.- Ofrenda en una milpa de Sierra Madre (Jalisco) 


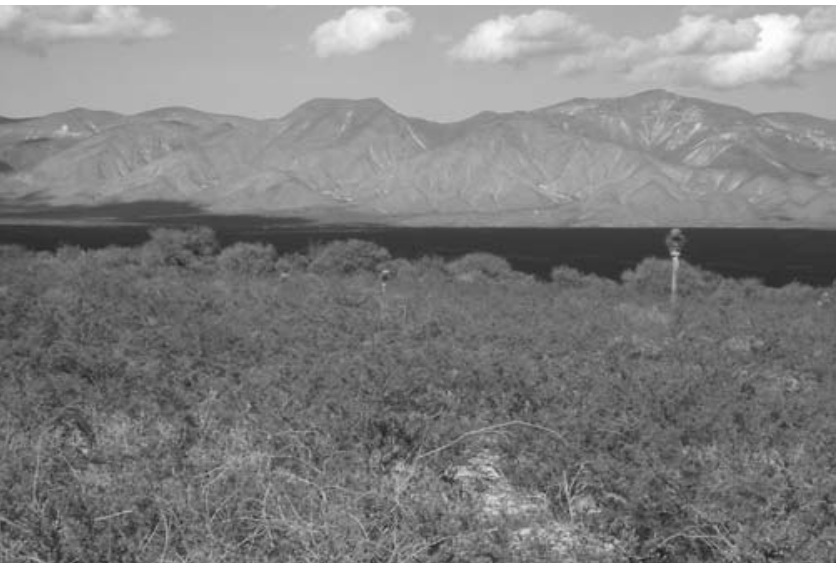

Fotografía 10.- Matorral desértico micrófilo en Huiricuta. Al fondo la Sierra de Catorce (San Luis Potosí)

culturales como un bien mixto, natural y cultural (Tavares, 2004). La Lista Indicativa es un instrumento estratégico de planificación para los Estados Parte de la Convención del Patrimonio Mundial Natural y Cultural de la UNESCO, y la base de evaluación del "valor universal excepcional" de cada bien propuesto. Sirve además como plataforma de un proceso de trabajos técnicos y de gestiones, para finalmente presentar la nominación ante el Comité de la Convención. La protección legal de la Ruta Huixrárica y sus paisajes vinculados a lo largo de los estados atravesados es justamente parte de este proceso. De forma complementaria añadir que el centro histórico de la ciudad de Zacatecas está inscrito como bien cultural desde 1993 en la Convención del Patrimonio Mundial Natural y Cultural de la UNESCO.

El tiempo ritual indígena, que busca una identificación profunda de las personas con los fenómenos naturales, ha logrado sobrevivir en un medio utilitario, de cambio acelerado y degradación. Con el fin de asegurar su continuidad, parece obligado alentar y reclamar un trato especial en todo lo concerniente a la salvaguardia y revitalización del patrimonio natural y cultural presente en el territorio por donde discurren estos itinerarios culturales. Los avances y logros obtenidos hasta el momento deben de alentar la formación de nuevas sinergias que fomenten la cooperación y el entendimiento entre los diferentes ámbitos que aquí convergen. En este sentido es vital que los tomadores de decisiones continúen escuchando los criterios, razones y demandas emitidas por la comunidad huichol y por la sociedad científica y conservacionista, y fomenten así el acercamiento de posiciones y la aplicación de herramientas eficaces de conservación y desarrollo. Asimismo es necesario intensificar la participación activa de los actores implicados (usuarios y vecinos de las Ruta, huicholes y mestizos) en pro de la preservación, rescate y revitalización de un patrimonio intangible y secular desarrollado al margen de la arquitectura monumental, y de su contraparte paisajística y natural. Ello si cabe tiene aún más sentido y urgencia al tratarse México de un país megadiverso con graves problemas de erosión de su patrimonio biológico y cultural.

Urge por tanto la aplicación de medidas consensuadas entre los diferentes actores implicados para dar solución a los problemas detectados durante los años de trabajo de campo empleados en la diagnosis aquí presentada.

\section{Referencias bibliográficas}

Arriaga, L., Espinoza, J. M., Aguilar, C., Martínez, E., Gómez, L. \& Loa, E. (2000). Regiones terrestres prioritarias de México. Escala 1:1.000.000. Disponible en: http://www.conabio.gob.mx

Beltrán, J. C. (2001). La Exploración de la Costa del Pacífico en el Occidente de Mesoamérica y los Contactos con Sudamérica y con otras Regiones Culturales. Universidad Autónoma de Nayarit, Consejo Nacional para la Cultura y las Artes - CONACULTA - e Instituto Nacional de Antropología e Historia - INAH -.

Broda, J. (2001). Ritos mexicas en los cerros de la cuenca: los sacrificios de niños. En: J. Broda et al. (Eds.). Montaña en el paisaje ritual. Consejo Nacional para la Cultura y las Artes - CONACULTA -, Instituto Nacional de Antropología e Historia -INAH-, Universidad Nacional Autónoma de México -UNAM-. 279-288.

CHAC (2001). Plan de Manejo de la Reserva Natural y Cultural de Huiricuta. Manuscrito. Conservación Humana Asociación Civil.

CHAC (2004). Inventario de Sitios Sagrados, Cahuís y otros paisajes culturales. Plan de Rescate de la Ruta Tradicional a Huiricuta. Manuscrito. Conservación Humana Asociación Civil.

CONABIO (2004). Regionalización. Disponible en http://www.conabio.gob.mx/conocimiento/ regionalizacion/doctos/regionalizacion.htm.

Dömpke, S. (1998). International instruments for the protection of indigenous cultures and lands. En: S. Dompke \& M. Succow (Eds). Cultural Landscapes and Natural Conservation in Nothern Eurasia. Naturschutzbund Deutschland. 42-48.

Fernández, H \& Becerra, G. (1995). Reservas de la biosfera y otras áreas naturales protegidas de México. Instituto Nacional de Ecología - INE - , Secretaría de Medioambiente Recursos Naturales y Pesca - SEMARNAP -, y Comisión Nacional para el Conocimiento y Uso de la Biodiversidad - CONABIO -. México DF

Fernández , H. \& G. Azcárate, J. (2005). El escenario de la ruta huichol a Huiricuta por los sitios sagrados naturales. Hereditas 13: 40-49.

Hers, M.A. (2000). La sombra de los desconocidos: los no mesoamericanos en los confines tolteca-chichimecas. En: Braniff, E. (Ed.). La Gran Chichimeca. Comisión nacional para la Cultura y las Artes - CONACULTA -. México DF.

INEGI (2006). Anuario Estadístico del Estado de Jalisco. Disponible en : http//www.inegi.gob.mx 
Lira, R. 2003. La organización colonial en la Sierra del Nayar de 1530 a 1722: un espacio pluridimensional, Tesis de Licenciatura, Historia, Facultad de Filosofía y Letras, UNAM, México DF.

Mittermier, R., Myers, N. \& Goettsch-Mittermier, C. (1999). Hotspots: Earth's biologically richest and most endangered terrestrial ecoregions. Conservation International \& Sierra Madre. México DF.

Nieves, G., Vázquez, J.A., M. Cházaro, B. \& Vázquez, M. (2004). Uso tradicional de la flora de la región Huichola. En: Vázquez, J.A. et al. (Eds.). Flora del Norte de Jalisco y etnobotánica huichola. Univ. de Guadalajara. 93 - 101.

Olson, D.M. \& Dinerstein, E. (2002). The Global 200: Priority Ecoregion for Global Conservation. Annals of the Missouri Botanical Garden 89: 199 - 224.

Rzedowski, J. (1991). Diversidad y orígenes de la flora fanerogámica mexicana. Acta Botanica Mexicana 14: 3 - 21.

Suárez Inclán, M. R. (2005). Los itinerarios culturales. Hereditas 13: 8 -13.

Tavares, E. (2004). El patrimonio de México y su valor universal. Lista indicativa 2004.
CONACULTA - INAH. Dirección de Patrimonio Mundial. México D.F.

Toledo, V. \& Ordóñez, M. J. (1998). El panorama de la biodiversidad en México: una revisión de los hábitats terrestres. En: T. P. Ramamoorthy et al. (Eds.). Diversidad biológica de México: orígenes y distribución: 739 -757.

Von Droste, B., Plachter, H. \& M. Rössler (1995). Cultural Landscapes of Universal Value - Components of a Global Strategy. Gustav Fischer Verlag, Jena, Stuttgart, New York, in cooperation with UNESCO.

Weigand, P.C. (1992). Ensayos del Gran Nayar entre coras, huicholes y tepehuanos. CEMCA, INI y Colegio de Michoacán. México DF.

Weigand, P.C. (2002). Estudio Histórico y Cultural sobre los Huicholes. Universidad de Guadalajara. Jalisco, México.

Weigand, P.C. \& García, A. (2000). Huichol society before the arrival of the spanish. Journal of Southwest, 42 (1): 1236. 